
\title{
3 Research Square \\ The effect of educational intervention based on precede proceed model on life quality in hypertensive patients
}

\section{Farbod Ebadi Fard Azar}

Iran University of Medical Sciences School of Behavioral Sciences and Mental Health

Mahnaz Solhi

Iran University of Medical Sciences School of Behavioral Sciences and Mental Health

Nemam Ali Azadi

Iran University of Medical Sciences School of Behavioral Sciences and Mental Health

Arash Ziapour

Kermanshah University of Medical Sciences

Javad Yoosefi Lebni

Iran University of Medical Sciences School of Behavioral Sciences and Mental Health

Fakhreddin Chaboksavar ( $\nabla$ fchaboksavar@yahoo.com )

Iran University of Medical Sciences https://orcid.org/0000-0003-4285-3178

Research

Keywords: Precede Proceed, Quality of life, Hypertension

Posted Date: January 2nd, 2020

DOI: https://doi.org/10.21203/rs.2.19628/v1

License: (9) (i) This work is licensed under a Creative Commons Attribution 4.0 International License. Read Full License 


\section{Abstract}

Background: Hypertension is considered as one of the major risk factors for cardiovascular diseases killing over 9 million people worldwide each year .

Methods: This experimental study was performed in 90 patient's hypertension attending health centers affiliated to karaj University of Medical Sciences. The subjects were randomly assigned into two groups of intervention $(n=45)$ and control $(n=45)$. The data were collected through questionnaires. Educational intervention was designed based on PRECEDE-PROCEED model and implemented in the intervention group. Data were collected three times prior to the intervention, 1 month after the intervention, and 3 months after the educational intervention. Data were analyzed using SPSS software and statistical methods number, percentage, mean, standard deviation and repeated measure test.

Results: The results showed that the mean score of various domains of life quality and total score of life quality in the intervention group increased significantly compared to the control group after the educational intervention.

Conclusions: The results showed that design and implementation of educational program based on PRECEDE-PROCEED model is effective in improving the life quality of hypertensive patients .

\section{Background}

Hypertension is considered as one of the major risk factors for cardiovascular diseases killing over 9 million people worldwide each year [1] .This disease is asymptomatic and the person may suffer from it for years unknowingly [2] and as it has no specific symptoms, it will not be diagnosed unless it causes serious defects and disorders [3]. Hypertension has affected about 50 million Americans and more than 600 million people worldwide [4] .According to studies done in various provinces of Iran, the prevalence of this disease is estimated to be 17 to $25 \%$ among adults and its prevalence among men is more than women $[5,6]$. Regarding this, the results of other studies recommend the need to pay more attention to the life quality of hypertensive patients [7-9]. The World Health Organization (WHO) defines life quality as the individuals' understanding of their position in life in terms of culture, value system, goals, expectations, standards, and priorities $[10,11]$. This concept involves one's physical health, psychological status, independence degree, social relationships, and beliefs [12]. In a study entitled "The effect of hypertension on life quality," Carvalho et al., showed that hypertensive people had a lower life quality compared to those with normal blood pressure $[13,14]$. The study used PRECEDE-PROCEED model to improve the life quality of hypertensive patients, introduced as a successful model in many clinical and field trials $[15,16]$. This model provides a framework for health care managers and policy makers to have effective evaluation and analysis according to various situations in curriculum design. Moreover, this model is a complete framework for evaluating health and life quality needs $[17,18]$. In this model, different factors are considered that form health status and help planners to reach a centralized set of factors for intervention purposes [19]. PRECEDE-PROCEED model presents a framework by which 
predisposing factors (knowledge, attitude, and perceptions), reinforcing factors (influence of others, family, and peers) and enabling factors (availability of resources and skills) are considered as factors affecting behavior in educational diagnosis. In fact, the most useful application of this model is to explain behavior-related factors [20]. Given the significance of life quality in hypertensive patients and the role of education in improving the life quality in these patients, the present study tried to specify the effect of educational intervention according to PRECEDE-PROCEED model on life quality in hypertensive patients.

\section{Methods}

\section{Study design}

This experimental study was performed in 90 patient's hypertension attending health centers affiliated to karaj University of Medical Sciences. The subjects were randomly assigned into two groups of intervention $(n=45)$ and control $(n=45)$. Inclusion criteria were personal consent, having a hypertension record, and exclusion criteria were lack of consent from self or family, death, age less than 30 years and over 70 years, and having a specific illness preventing continued collaboration with the present study. The data were collected after selecting the samples with inclusion criteria. The data were collected through 2 questionnaires. The first questionnaire was a demographic questionnaire. It included one item to examine the demographic variables such as sex, age, job, education, marital status, family history of disease and length of disease. The second questionnaire was the World Health Organization Quality of Life Questionnaire (WHOQOL-BREF) (SF-26). It is a 26-item questionnaire assessing four aspects of physical health (7 questions), mental health (6 questions), social relationships (3 questions), and environmental health (8 questions) with 24 questions.and two questions that did not belong to any of the domains assessed the general health and quality of life. The validity and reliability of the quality of life questionnaire were also confirmed by correlation values and Cronbach's alpha of above 0.7 [21].Data were collected three times prior to the intervention, 1 month after the intervention, and 3 months after the educational intervention. Educational intervention was designed based on PRECEDE-PROCEED model and implemented in the intervention group. In the intervention, the low life quality in hypertensive patients was considered as the most important health problem and individual, behavioral and environmental factors affecting the life quality of these patients were examined. In the behavioral evaluation stage, the target behavior was identified according to significance and variability. Then, in the educational and ecological evaluation stage, predisposing factors (including patient knowledge and attitude), enabling factors (including access to educational resources and health centers), and reinforcing factors (including encouragement and support of hypertensive patients and family members) were evaluated, and specific program goals were identified accordingly and the training program was prepared for the intervention group and administered in 5 training sessions. This educational program used lectures, group discussions and questions about nutrition, physical activity, using medication, and stress management and the impact of the above on patients' life quality and the preset goals were evaluated during the implementation of the educational program. This evaluation led to a training program tailored to the 
preset goals. Ultimately, the hypertensive training package was given to them. One month and three months after the intervention, the questionnaires were re-completed and data were collected. After collecting the questionnaires, data were analyzed using SPSS software and statistical methods (number, percentage, mean, standard deviation and repeated measure test).

\section{Results}

The results of the present study showed that the mean age of patients in the control group was 51.44 years, in the intervention group, it was 52.77 years. The mean duration of hypertension was 3.35 years in the control group, 3.93 years in the intervention group. Other results related to demographic characteristics are shown in Table 1. The results of the Table 1 show that most participants were male, so that $66.7 \%$ and $62.2 \%$, of the patients were male in the control and intervention groups, respectively. $100 \%$ of the patients in all tow groups were married. With regard to the level of education, only $8.9 \%$ of the patients in the control group had academic level of education, and this rate was $6.7 \%$, for the intervention group, and rest of the patients did not have academic level of education. With regard to job status of the patients in all tow groups, most of them were self-employed and housewives. In the control group, 31.1\% of the patients were self- employed and $31.1 \%$ were housewives. In the intervention group, $28.9 \%$ of the patients were self-employed and $26.7 \%$ were housewives. With regard to family history of hypertension, in the control group, $57.8 \%$ of patients had family history of hypertension, in the intervention group, $53.3 \%$ had family history of hypertension. 
Table 1

Demographic characteristics of hypertensive patients based on gender, marital status, education level, job and Family history of hypertension in control and intervention groups

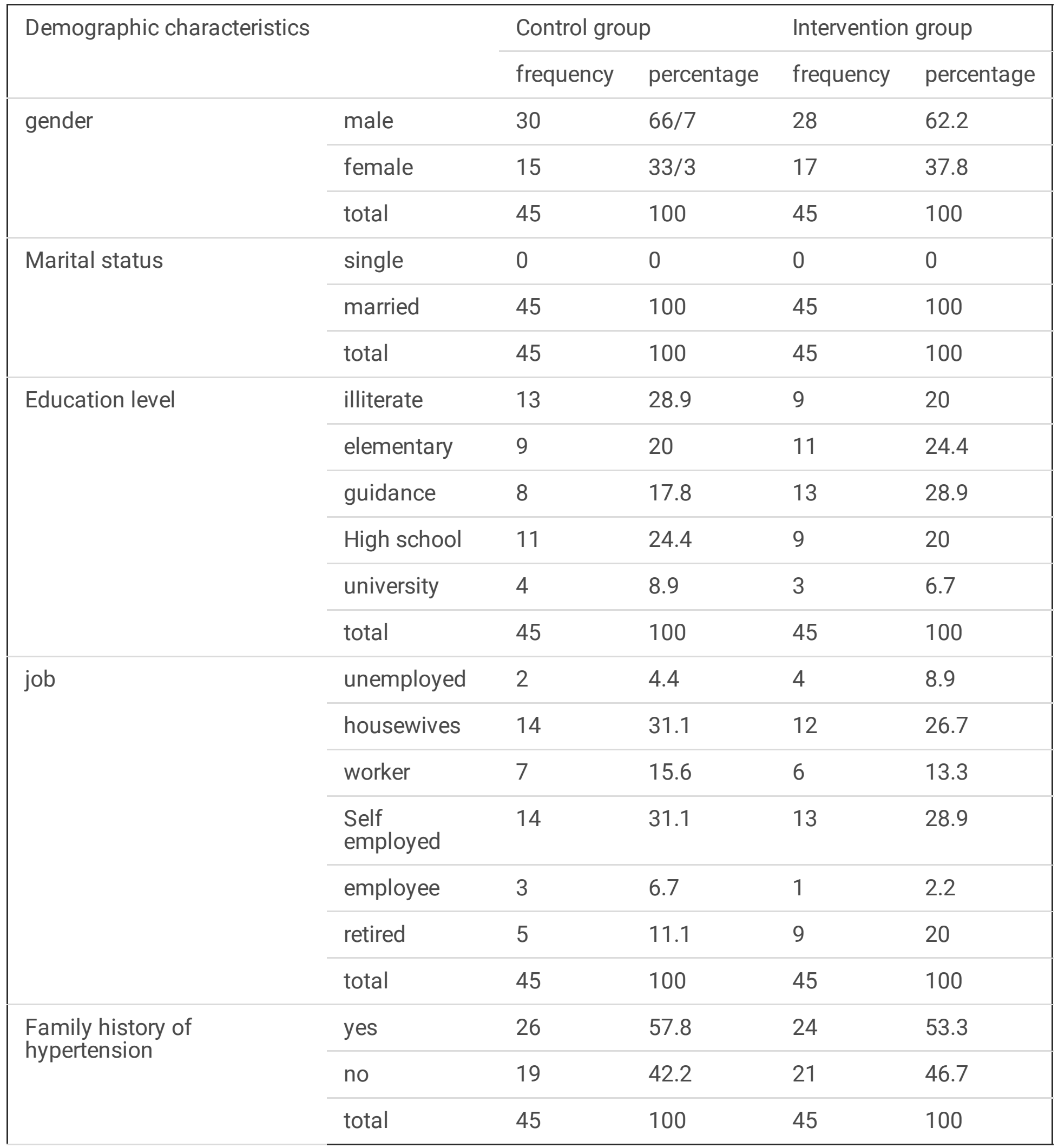


Table 2

Results of repeated measure test to compare various domains of life quality in control and intervention groups, prior to intervention, 1 month after intervention and 3 months after educational intervention

\begin{tabular}{|c|c|c|c|c|c|c|c|}
\hline \multirow{2}{*}{$\begin{array}{l}\text { quality of } \\
\text { life domains }\end{array}$} & \multirow[t]{2}{*}{ Time } & \multicolumn{3}{|c|}{ Control group } & \multicolumn{3}{|c|}{ Intervention group } \\
\hline & & Mean & SE & $\begin{array}{l}\text { Confidence } \\
\text { interval } \\
95 \%\end{array}$ & Mean & SE & $\begin{array}{l}\text { Confidence } \\
\text { interval } \\
95 \%\end{array}$ \\
\hline \multirow[t]{3}{*}{ physical domain } & $\begin{array}{l}\text { Pre } \\
\text { intervention }\end{array}$ & 18.77 & 0.346 & $\begin{array}{l}19.46- \\
18.09\end{array}$ & 18.86 & 0.346 & $\begin{array}{l}19.55- \\
18.18\end{array}$ \\
\hline & $\begin{array}{l}1 \text { month after } \\
\text { intervention }\end{array}$ & 17.85 & 0.338 & $\begin{array}{l}18.52- \\
17.18\end{array}$ & 24.06 & 0.239 & $\begin{array}{l}24.53- \\
23.59\end{array}$ \\
\hline & $\begin{array}{l}\text { 3month after } \\
\text { intervention }\end{array}$ & 18.86 & 0.346 & $\begin{array}{l}19.55- \\
18.18\end{array}$ & 23.55 & 0.265 & $\begin{array}{l}24.08- \\
23.03\end{array}$ \\
\hline \multirow[t]{3}{*}{$\begin{array}{l}\text { psychological } \\
\text { domain }\end{array}$} & $\begin{array}{l}\text { Pre } \\
\text { intervention }\end{array}$ & 15.13 & 0.286 & $\begin{array}{l}15.69- \\
14.56\end{array}$ & 15.57 & 0.286 & $\begin{array}{l}16.14- \\
15.01\end{array}$ \\
\hline & $\begin{array}{l}\text { 1month after } \\
\text { intervention }\end{array}$ & 14.55 & 0.280 & $\begin{array}{l}15.10- \\
13.99\end{array}$ & 20.75 & 0.216 & $\begin{array}{l}21.18- \\
20.32\end{array}$ \\
\hline & $\begin{array}{l}\text { 3month after } \\
\text { intervention }\end{array}$ & 14.56 & 0.280 & $\begin{array}{l}15.14- \\
13.99\end{array}$ & 20.13 & 0.216 & $\begin{array}{l}20.56- \\
19.70\end{array}$ \\
\hline \multirow[t]{3}{*}{ social domain } & $\begin{array}{l}\text { Pre } \\
\text { intervention }\end{array}$ & 6.87 & 0.194 & $7.25-6.50$ & 7.51 & 0.199 & $7.90-7.11$ \\
\hline & $\begin{array}{l}1 \text { month after } \\
\text { intervention }\end{array}$ & 7.40 & 0.199 & $7.79-7.00$ & 9.62 & 0.144 & $9.90-9.33$ \\
\hline & $\begin{array}{l}\text { 3month after } \\
\text { intervention }\end{array}$ & 6.85 & 0.194 & $7.23-6.46$ & 9.62 & 0.144 & $9.90-9.33$ \\
\hline \multirow[t]{3}{*}{$\begin{array}{l}\text { environmental } \\
\text { domain }\end{array}$} & $\begin{array}{l}\text { Pre } \\
\text { intervention }\end{array}$ & 18.73 & 0.458 & $\begin{array}{l}19.64- \\
17.82\end{array}$ & 19.46 & 0.458 & $\begin{array}{l}20.37- \\
18.56\end{array}$ \\
\hline & $\begin{array}{l}1 \text { month after } \\
\text { intervention }\end{array}$ & 17.12 & 0.449 & $\begin{array}{l}18.01- \\
16.24\end{array}$ & 25.22 & 0.367 & $\begin{array}{l}25.94- \\
24.49\end{array}$ \\
\hline & $\begin{array}{l}\text { 3month after } \\
\text { intervention }\end{array}$ & 19.2 & 0.458 & $\begin{array}{l}17.95- \\
20.45\end{array}$ & 26.86 & 0.356 & $\begin{array}{l}27.57- \\
26.16\end{array}$ \\
\hline \multirow[t]{3}{*}{$\begin{array}{l}\text { total score of } \\
\text { quality of life }\end{array}$} & $\begin{array}{l}\text { Pre } \\
\text { intervention }\end{array}$ & 65.24 & 1.20 & $\begin{array}{l}67.62- \\
62.86\end{array}$ & 66.82 & 1.20 & $\begin{array}{l}69.20- \\
64.43\end{array}$ \\
\hline & $\begin{array}{l}1 \text { month after } \\
\text { intervention }\end{array}$ & 65.42 & 1.20 & $\begin{array}{l}67.90- \\
62.95\end{array}$ & 87.55 & 0.801 & $\begin{array}{l}89.14- \\
85.97\end{array}$ \\
\hline & $\begin{array}{l}\text { 3month after } \\
\text { intervention }\end{array}$ & 66.03 & 1.20 & $\begin{array}{l}63.48- \\
69.11\end{array}$ & 84.71 & 0.871 & $\begin{array}{l}86.43- \\
82.98\end{array}$ \\
\hline
\end{tabular}


The results of Table 2 showed that in the control group and at the beginning of the study, $95 \%$ confidence interval for the mean score of quality of life in the physical domain was in the range of 18.09-19.46, and it was 14.56-15.69 for psychological domain, 6.50-7.25 for social domain, 17.82-19.64 for environmental domain, and 62.86-67.62 for total score of quality of life. One month after starting the study, $95 \%$ confidence interval for the mean score of quality of life in the physical domain was in the range of 17.18-18.52, and it was 13.99-15.10 for psychological domain, 7-7.79 for social domain, 16.24-18.01 for environmental domain, and 64.43-69.20 for total score of quality of life. Three month after starting the study, $95 \%$ confidence interval for the mean score of quality of life in the physical domain was in the range of 18.18-19.55, and it was 13.99-15.14 for psychological domain, 6.46-7.23 for social domain, 17.95-20.45 for environmental domain, and 63.48-69.11 for total score of quality of life. As the confidence interval between the various domains of life quality and overall life quality score, overlap one month after the beginning of the study and 3 months after the beginning of the study relative to beginning of the study, one can conclude that repeated measure test did not show any significant differences in the control group.

But in the intervention group before the educational intervention, $95 \%$ confidence interval for the mean score of quality of life in the physical domain was in the range of $18.18-19.55$, and it was 15.01-16.14 for psychological domain, 7.11-7.90 for social domain, 18.56-20.37 for environmental domain, and 64.43-69.20 for total score of quality of life. One month after the educational intervention, $95 \%$ confidence interval for the mean score of quality of life in the physical domain was in the range of 23.59-24.53, and it was 20.32-21.18 for psychological domain, 9.33-9.90 for social domain, 24.4925.94 for environmental domain, and 85.97-89.14 for total score of quality of life. three month after the educational intervention , $95 \%$ confidence interval for the mean score of quality of life in the physical domain was in the range of 23.03-24.08, and it was 19.70-20.56 for psychological domain, 9.33-9.90 for social domain, 26.16-27.57 for environmental domain, and 82.98-86.43 for total score of quality of life. As the confidence interval between the various domains of life quality and overall life quality score, did not overlap one month after the educational intervention and 3 months after the educational intervention relative to before the educational intervention, one can conclude that repeated measure test did show significant differences in the intervention group.

\section{Discussion}

The results of the present study show that the educational intervention according to the steps of the PRECEDE-PROCEDURE model has significantly increased all aspects of the life quality of the experimental group compared to the control. This shows the necessity of using planned and theory-based educational interventions to improve the life quality in hypertensive patients. Regarding this, a study conducted by Dehdari et al. confirms the effect of PRECEDE-PROCEED model training on enhancing the life quality of patients after coronary artery bypass surgery [22]. In a study by Calano et al. based on PRECEDE-PROCEED model for blood pressure control, adherence and control of systolic and diastolic blood pressure significantly increased after two months [23]. Moreover, a study by Hosseini et al. based on PRECEDE-PROCEED model on hypertensive patients showed a significant increase in physical activity 
in the intervention group and a significant improvement in their diet compared to the control group [24]. The results of Pournaghash Tehrani and Etemadi indicated the effect of PRECEDE-PROCEED model on improving the life quality of coronary artery bypass graft patients [25]. The results of LI et al. showed that PRECEDE-PROCEED model can be used as an effective model in assessing health needs for improving life [26]. The results of a study by Matin et al. entitled "The effect of educational intervention based on PRECEDE model on the improving life quality in the elderly" showed a significant difference in the total score of life quality after intervention in the experimental group [27]. Moreover, the results of a study by Doshmagir et al. entitled "The effect of educational intervention based on PRECEDE model on the improvement of life quality in the elderly" showed a significant difference between different aspects of life quality and total score of life quality after educational intervention [28]. All of the above studies are consistent with the present study and according to these results, it is necessary to design educational intervention based on PRECEDE model to improve the life quality of hypertensive patients. The results of other studies based on PRECEDE-PROCEED model show that this pattern is effective in enhancing life quality. The results of the study by Shore concerning improving life quality in relation to epilepsy [29], the study by Wang et al. regarding life quality in the elderly with chronic heart failure [30], as well as the study by Zhu et al. on the effect of educational intervention on improving physical health, as one of the dimensions of life quality of immigrant women workers [31] are in this regard. One has to note that the role of educational interventions in improving the life quality in different people, especially chronic diseases like hypertension, should not be ignored. Moreover, if these interventions are run using comprehensive models like PRECEDE-PROCEED model, it will certainly give better results as models like PRECEDE-PROCEED guide a systematic movement towards performing healthy behaviors in the individual. Among the limitations of the study, one can state the use of self-reporting method for data collection.

\section{Conclusion}

The results showed that design and implementation of educational program based on PRECEDEPROCEED model is effective in improving the life quality of hypertensive patients and can be used as a framework for designing interventions to improve the life quality in these patients.

\section{Abbreviations}

EIB: Educational Intervention Based; MPP: precede proceed model; LQHP: Life Quality in Hypertensive Patients

\section{Declarations}

\section{Acknowledgments}

This article was derived from a PHD dissertation on Health Education and Health Promotion under the ID code of IRCT20170814035698N2 approved by the Faculty of Health of Iran University of Medical 
Sciences. The researchers of this research thereby appreciated hypertension patients referred to Karaj health centers.

\section{Authors'contributions}

FCH, MS and JYL conceived and designed the study and finalized the methodology and tools used. FEFA, NAA, and AZ collected the data and analyzed and drafted the manuscript. All the authors made significant contributions in the manuscript writing and finalizing of the manuscript. The final manuscript has been read and approved by all the authors.

\section{Funding}

There was no source of funding.

\section{Availability of data and materials}

Authors report that the data supporting their findings can be publicly shared.

\section{Ethics approval and consent to participate}

This study was drawn from a research project (No. IR.IUMS.REC. 1395.9321108003) sponsored by the Deputy of Research and Technology at IUMS.

\section{Consent for publication}

Not applicable.

\section{Competing interests}

The authors declare that they have no competing interests

\section{Author details}


${ }^{1}$ Professor, Department of Health Services and Health Education, School of Health, Iran University of Medical Sciences, Tehran, Iran. ${ }^{2} \mathrm{PhD}$, Associate Professor, Department of Health Services and Health Education, School of Health, Iran University of Medical Sciences, Tehran, Iran. ${ }^{3} \mathrm{PhD}$, Assistant Professor, Department of Biostatistics, School of Health, Iran University of Medical Sciences, Tehran, Iran. ${ }^{4} \mathrm{PhD}$ Student of Health Education and Health Promotion, Health Institute, Kermanshah University of Medical Sciences, Kermanshah, Iran. ${ }^{5} \mathrm{PhD}$ student health education and health promotion, school of health, Iran university of medical sciences, Tehran, Iran. ${ }^{6} \mathrm{PhD}$ student health education and health promotion, school of health, Iran university of medical sciences, Tehran, Iran.

\section{References}

1. Joffres M, Falaschetti E, Gillespie C, Robitaille C, Loustalot F, Poulter N, et al. Hypertension prevalence, awareness, treatment and control in national surveys from England, the USA and Canada, and correlation with stroke and ischaemic heart disease mortality: a cross-sectional study. BMJ Open 2013;3(8):e003423.

2. Vanhoof JM, Delcroix M, Vandevelde E, Denhaerynck K, Wuyts W, Belge C, et al. Emotional symptoms and quality of life in patients with pulmonary arterial hypertension. J Heart Lung Transplant 2014;33(8):800-8.

3. Majumdar A, Chinnakali P, Vinayagamoorthy V, Daya PA, Shidam UG, Roy G. Opportunistic screening for hypertension and selected cardiovascular risk factors among adults attending a primary health center in Puducherry, India. Int J Prev Med 2014;5(12):1616.

4. Perez V, Chang ET. Sodium-to-potassium ratio and blood pressure, hypertension, and related factors. Advan Nutrit 2014;5(6):712-41.

5. Eghbali M, Khosravi A, Feizi A, Mansouri A, Mahaki B, Sarrafzadegan N. Prevalence, awareness, treatment, control, and risk factors of hypertension among adults: a cross-sectional study in Iran. Epidem Health 2018;40.

6. Kazemi T, Hajihosseini M, Mashreghimoghadam H, Azdaki N, Ziaee M. Prevalence and determinants of hypertension among Iranian adults, Birjand, Iran. International journal of preventive medicine. 2017;8.

7. SHAMSI A, REFAHI A, MALMIR M, MOLLAHADI M, EBADI A. Comparison of quality of life in military Person Without Hypertension 2012.

8. Theodorou M, Kaitelidou D, Galanis P, Middleton N, Theodorou P, Stafylas P, et al. Quality of life measurement in patients with hypertension in Cyprus. Hellenic J Cardiol 2011;52(5):407-15.

9. ur Rehman A, Naeem F, Abbas S, Ashfaq F, Hassali MAA. Utilization of short message service (SMS) in non-pharmacological management of hypertension. A pilot study in an URBAN public hospital of Multan, Pakistan. J Public Health 2019;27(5):561-7.

10. Cui J, Fang F, Shen F, Song L, Zhou L, Ma X, et al. Quality of life in patients with advanced cancer at the end of life as measured by the McGill quality of life questionnaire: a survey in China. J Pain 
Symptom Manag 2014;48(5):893-902.

11. Al-Jabi SW, Sa'ed HZ, Sweileh WM, Wildali AH, Saleem HM, Aysa HA, et al. Assessment of healthrelated quality of life among hypertensive patients: a cross-sectional study from Palestine. J Public Health 2014;22(3):277-86.

12. Rimaz S, Abolghasemi J, Seraji S. The relationship of different dimensions of social support with older adults' quality of life in the 8th district of Tehran in 2013. J Educ Community Health 2015;2(1):29-37.

13. Carvalho MVd, Siqueira LB, Sousa ALL, Jardim PCBV. The influence of hypertension on quality of life. Arquivos brasileiros de cardiologia 2013;100(2):164-74.

14. Chaudhari HE, Patil SD. Assessment of hazardous elements of metabolic syndrome in hypertensive patients to defend them from cardiovascular risk in tribal region. Diabet Metabol Syndrome: Clin Res Rev 2019 Mar 1;13(2):925-31.

15. Shahnazi H, Tabar IM, Azarbin S, Hassanzadeh A, Charkazi A, Moodi M. Impact of education based on precede model on knowledge, attitude and behavior of grade two guidance school girls regarding Iron Deficiency Anemia (IDA) in Isfahan, Iran. 2012.

16. Kamal NN, Kamel EG, Eldessouki KH, Ahmed MG. Health-related quality of life among hemodialysis patients at El-Minia University Hospital, Egypt. J Public Health 2013;21(2):193-200.

17. Hatami F. The effects of a safety educational intervention on promoting safety behavior at textile workers. Hormozgan Med J 2013;17(4):333-45.

18. Raikou VD, Gavriil S. Body-mass index and the risk of albuminuria in hypertensive patients with a poor estimated glomerular filtration rate and the potential role of diabetes mellitus. Diabet Metabol Syndrome: Clin Res Rev 2019 1;13(2):1041-6.

19. Porter CM. Revisiting Precede-Proceed: A leading model for ecological and ethical health promotion. Health Educ J 2016;75(6):753-64.

20. Babaei-Sis M, Ranjbaran S, Mahmoodi H, Babazadeh T, Moradi F, Mirzaeian K. The effect of educational intervention of life style modification on blood pressure control in patients with hypertension. J Educ Community Health 2016;3(1):12-9.

21. Nejat S, Montazeri A, Holakouie Naieni K, Mohammad K, Majdzadeh S. The World Health Organization quality of Life (WHOQOL-BREF) questionnaire: Translation and validation study of the Iranian version. J School Public Health Instit Public Health Res 2006;4(4):1-12.

22. Rastgarimehr B, Afkari ME, Solhi M, Taghdisi MH, Mansourian M, Shafieyan Z, et al. Relationship between the educational stage of PRECEDE model and quality of life improvement in the elderly affiliated with Tehran culture house for the aged. Iran J Diabet Metabol 2014;13(6):469-78.

23. McDonald TJ, Colclough K, Brown R, Shields B, Shepherd M, Bingley P, et al. Islet autoantibodies can discriminate maturity-onset diabetes of the young (MODY) from Type 1 diabetes. Diabet Med 2011;28(9):1028-33.

24. Hosseini F, Farshidi H, Aghamolaei T, Madani A, Ghanbarnejad A. The impact of an educational intervention based on PRECEDE-PROCEED model on lifestyle changes among hypertension patients. 
Iran J Health Educ Health Promot2014;2(1):17-27.

25. Pournaghash-Tehrani S, Etemadi S. ED and quality of life in CABG patients: an intervention study using PRECEDE-PROCEED educational program. Int J Impot Res 2014;26(1):16-22.

26. Li Y, Cao J, Lin H, Li D, Wang Y, He J. Community health needs assessment with precede-proceed model: a mixed methods study. BMC Health Services Res 2009;9(1):181.

27. Ranjbaran S, Dehdari T, Sadeghniiat-Haghighi K, Majdabadi MM. Poor sleep quality in patients after coronary artery bypass graft surgery: an intervention study using the PRECEDE-PROCEED model. $J$ Tehran UnivHeart Center 2015;10(1):1-7.

28. Doshmangir P, Shirzadi S, Tagdisi MH, Doshmangir L. Effect of an educational intervention according to the PRECEDE model to promote elderly quality of life. J Educ Community Health 2014;1(2):1-9.

29. Shore CP, Perkins SM, Austin JK. The Seizures and Epilepsy Education (SEE) program for families of children with epilepsy: a preliminary study. Epilepsy Behav 2008;12(1):157-64.

30. Wang Q, Dong L, Jian Z, Tang X. Effectiveness of a PRECEDE-based education intervention on quality of life in elderly patients with chronic heart failure. BMC Cardiovascular Disord 2017;17(1):262.

31. Zhu C, Geng Q, Yang H, Chen L, Fu X, Jiang W. Quality of life in China rural-to-urban female migrant factory workers: a before-and-after study. Health Q Life Outcom 2013;11(1):123. 